\section{COMBINED RAW MATERIALS BOARD}

$\mathrm{T}$ HE third annual report of the Combined Raw Materials Board covers the year ended January 26,1945 , and shows elearly that the international planning of the production and distribution of industrial raw materials, the world demand for which exceeds the supplies available, will long be required. The progress of the War during 1944, and the completion in large measure of the major planning tasks in the raw materials field in support of the war effort, permitted the two member Governments to review the Board's duties and terms of reference and to consider what modifications might be necessary in future.

The Board was designed as a war-time organization; but it is encouraging to learn that it has been decided, as a result of these discussions, that the Board shall continue in being for the duration of the War against Japan, and to operate under its existing terms of reference and with the increasing collaboration of the other United Nations most closely concerned. The text of a joint public announcement of January 19, 1945, which covers also the Combined Production and Resources Board and the Combined Food Board, is appended, and should remove the fear of any hasty jettisoning of the war-time machinery of economic partnership and control, and of the liberated countries of western Europe seeking to outbid each other or their more prosperous neighbours for scarce materials by independent buying in the markets of the world.

The report indicates a general improvement in 1944 in the raw materials position, and stringencies were arising less from shortages of raw materials than from other factors, particularly the shortage of labour for processing raw materials. The Board has been able to relax close control over certain grades of asbestos, balata, balsa wood, cobalt, mercury, mica, molybdenum, shellac, tantalite and tungsten, but on the other hand, sudden and unforeseen changes in the demand and supply position made it necessary to restore close control of antimony and zinc. Combined action was also necessary to deal with new shortages of jute, platinum, lead, casein, animal glue-making materials and goatskins, and the report refers to the way in which changes in military requirements and the needs of newly liberated countries prevent the guarantee of equilibrium. The acute dearth of natural rubber and of hard hemp persisted, and the Board urges that the conversion from the use of natural to the use of synthetic rubber should be vigorously pursued in all consuming countries. The situation with regard to hides and leather steadily worsened during 1944 , and is likely to be one of the most serious facing the Board during 1945. Arrangements have already been made to bring the United Nations Relief and Rehabilitation Administration and the governments of Europe financing their own reconstruction requirements into close working arrangements with the Board to ensure that the orderly flow of hides may continue as new claimants against the world's supply enter the picture.

Particularly during the latter half of 1944, the governments of the liberated areas were in constant consultation with the Board regarding their requirements of essential raw materials, and although no substantial deliveries were possible before the end of the year, these claimants may cause new stringen- cies in raw materials available for civilian use in the United States, Great Britain and elsewhere during 1945. Within the narrower range of scarce commodities such as hides and leather, lumber, paper and pulp, cordage fibres, jute and lead, the legitimate needs of Europe will curtail the quantity available for others, although on the other hand the industrial output of western Europe should soon help to counteract the current deficits in such items as tyres and textiles.

\section{MICROFILM AND OTHER MEANS OF DOCUMENTARY REPRODUCTION}

A $\mathrm{T}$ the nineteenth annual conference of the Association of Special Libraries and Information Bureaux held in December last, it was felt that justice could not be done to the photographic reproduction of documents by microfilm and other methods without a special conference on this subject alone. Such a conference was therefore held in London in the rooms of the Royal Society during June 1-2, under the auspices of the ASLIB Microfilm Service. Its three sessions drew a full gathering of some hundred and fifty librarians and other workers in bibliographical fields, including many from government departments, and a number of representatives of the photographic industry. The first two sessions were devoted largely to technical matters related to copying and reproduction processes, and the third and last session to the vexed question of copyright. At all three sessions the vigour of the discussions, quite as much as the high quality of the contributions of the principal speakers, provided a measure of the value of the conference; and if little was achieved in the way of proposals for that standardization which would do more than anything else to promote the use of this valuable new tool-a tool destined, some maintain, to transform research library practice - the conference did succeed in demonstrating the variety of purposes for which document-copying by photographic means is needed, and in suggesting some of the directions in which advances are likely to be most rapid.

After a brief speech of welcome had been made by Prof. A. V. Hill, who presided over the opening session, Mr. F. J. Tritton (of Ilford Limited) gave a clear and admirable survey of the principal photographic methods of document-copying and of the technical problems they involve, illustrating his remarks by reference to full-size paper reproductions, by the various processes, of a page of an ordinary journal comprising letterpress and illustrations in line, stipple and half-tone. For satisfactory reproduction of typographic matter, some overall gain in contrast is generally considered desirable, and while this does not affect the clarity of line and stipple illustrations, it gives poor reproduction of half-tone blocks. A compromise is therefore necessary, and since the greater bulk of material normally copied is purely typographic, materials of relatively high contrast are generally preferred; their development can, when necessary, be so modified as to reproduce half-tones satisfactorily. The processes can be classified as $(a)$ those needing a camera, yielding records either substantially full-size (for example, photostat, using paper) or of reduced size (microfilm), and (b) those requiring no camera, but employing straight contact-printing to give a full-size copy, among these 
being reflex processes, applicable to documents printed on both sides. Any of these processes can be made to yield a negative (the sole copy) or an unlimited number of positives (from a master negative). The choice of process depends much on the volume of work to be done, since gross costs are obviously affected by the cost of the apparatus needed in making the copy and in using it ; it depends also on the purpose of the work, since evidently if reduced bulk is important, whether for storage or transport, some such method as microfilm is essential.

Other processes were mentioned in the course of an animated discussion, among them in particular being the 'micro-print' processes which have recently attracted considerable attention, especially in America. A case in point was the 'micro-card' system which has been described at length by Fremont Rider, librarian of the Wesleyan University Library, in "The Scholar and the Future of the Research Library" (see Nature, 154, 655 ; 1944). Rider, impressed by the average rate of growth of American research libraries, which, he finds, double in size every sixteen years, has proposed that the back of the typical 5 in. $\times 3$ in. library index card should carry a reduced image of up to one hundred pages of the text of the document catalogued; and thus, in short, that the research library of the future would be housed on the back of its catalogue cards, the cards themselves being produced at a cheap rate and in relatively large editions by central reproducing agencies. Mr. Tritton believes that a special difficulty of this and other micro-print systems using high degrees of reduction, quite apart from the present lack of satisfactory reading apparatus, is the obliterat. ing effect of dust-particles settling during the copying of the original or in the course of printing. Other micro-print processes were mentioned in discussion, including one by Dr. Carl White of Columbia University, by which reduced copies of 25 pages of an original are offset-printed upon a single printed page of normal size.

Notwithstanding these developments, micro-film remains at present, in Great Britain and the United States, the medium most widely used for bulk reproduction work. A very pertinent discussion, therefore, was prompted by the second paper of the conference when Mrs. L. Moholy (director of the ASLIB Microfilm Service) reported on discussions she has had with Dr. L. A. Sayce on the important practical questions : whether perforated or unperforated film should be used, and whether a fixed frame-length should be adopted or a frame-length varying, at a fixed degree of reduction, with the length of the original document. Unperforated film offers greater economy in film area and therefore in weight, and has been employed by the ASLIB Microfilm Service, much of the output of which has been sent overseas. On most technical grounds it has much to commend it, but difficulties have arisen because unperforated film cannot be passed through the sprocket-driven apparatus which has for the most part been used in Britain.

An interesting discussion led to a suggestion that in future ASLIB should supply perforated film unless unperforated be specifically requested, since the former can be used in any reading apparatus. Similar divisions of opinion were clearly shown on the question of fixed frame vs. varying frame. The majority of speakers favoured the former, which simplifies apparatus problems (automatic selection of frames in reading and analysing machines) and makes for ease of filing and indexing of short lengths of film, though it can be somewhat wasteful of film when the page size of the originals varies.

A similar diversity of present-day practice was seen in the field of reading apparatus, described by Mrs. L. Moholy in an illustrated lecture on "Projectors and Reading Machines" at the second session of the conference. The discussion showed, so far as a synthesis of the diverse needs of different classes of user is at all possible, that the ideal microfilm reader would probably be a relatively light and portable apparatus giving an easily readable image projected on a white reflecting surface (rather than on a diffusely transmitting screen), the apparatus being adapted to take a film bearing images either along or across its width and having conveniently operable means of changing from one frame to another and of selecting a desired frame as quickly as possible, and at the same time taking up so little space on a desk as to leave plenty of room for notebooks, etc. If we add that the apparatus would have to be produced cheaply because, it was urged, the average research user would want a reader on his desk and not merely in the central library of his department, we realize that no such reader exists as yet. Reference was made in discussion to a small cheap folding reader made of cardboard, adapted to take a few frames of film, which was used during the War for supplying information to the F.F.I. in France, the folded card reader and the microfilm being dropped from the air.

It was stated by some speakers that most users of microfilm services prefer to have prints which can be read direct, and while this may be due in part to the lack of really satisfactory readers, there is no doubt that a print which can be filed for easy reference has many advantages for the research worker. The storage of microfilm and its resistance to wear were also mentioned. Work carried out in the United States and elsewhere has shown, Mr. Tritton said, that provided the photographic processing has been properly carried out, the age of a microfilm record should be at least as great as that of the original document. Exposure to tropical atmospheric conditions should be avoided by air-conditioning filmstorage compartments, but such steps are not necessary in temperate climates. As to wear in the course of handling, that appears to depend on the care taken by the user; but Mrs. Moholy emphasized that master copies should not be used in readers.

During this second session of the conference, at which Dr. C. H. Desch took the chair, Mr. G. R. Edwards (secretary of the Royal Society of Medicine) gave an account of the microfilm service which has been provided since the outbreak of war by that Society, as a means of providing its overseas members with information on request. It had been widely used, also, by the Director General of the Army Medical Services. Mr. Edwards pointed out that microfilms not only occupy a much smaller space than photostat copies, but also cost considerably less. It is certain that in future any library of standing will have a film reader and should be ready to use every type of technical device to disseminate its material. The use of such devices should, therefore, be taught in courses on librarianship.

The final session of the conference was in the form of a 'brains trust' on documentary reproduction and copyright, with Mr. G. S. W. Marlow, barrister-at-law (secretary of the Faraday Society), as chairman and question-master. The 'brains trust' consisted of 
Prof. J. D. Bernal, Mr. E. J. Carter, Dr. Arundell Esdaile, Dr. C. H. Desch and Mr. R. A. Lochner. The chairman opened the proceedings with a summary of the relevant parts of the law of copyright. The making of a photographic copy is obviously "reproduction of the original" within the meaning of the Acts, but since the Acts permit "fair dealing" with an original for the purposes of private study and research, the problem raised by photographic reproduction is largely "When is dealing fair ?" In the course of the answers to this question, in which the audience shared freely, Prof. Bernal thought that scientific workers have long been breaking the law not only for study but also for criticism. To him, "fair dealing" implied the question: Was the photocopying service one for which money could reasonably be asked by the owner of the copyright? If the copies were made for the use of one or two persons only, it would be very different from copies made for classteaching on a large scale. Dr. Esdaile amplified this by saying that fair dealing ceased when the commercial interests of the owner were injured. Mr. A. G. Dance, of the Ministry of Education, said that the matter is one of great consequence, and some decision must soon be reached because the Ministry was hoping to see a very considerable increase in the use of film strip after the War. Several speakers urged the advertising value of photocopies. If production of photocopies, so far from reducing the demand for the original, stimulated such a demand (as has happened with the B.B.C. in the concert field), then injury to the owner of the copyright could scarcely be said to have occurred. Mr. Tritton went further, stating that the authors of much of the material now being microfilmed are individual scientific men and other professional workers whose greatest reward lies in the wide dissemination of their works, for which they rarely receive payment in money. Mr. Chilton added that the copying of individual articles in journals puts these articles at the disposal of research workers who only in rare instances could be expected to subscribe to the original journals, especially when account is taken of the widespread scatter of material on any one subject throughout the thousands of current scientific and professional periodicals. It was generally agreed, however, that since publishing bodies are inevitably business concerns, copyright problems cannot be got round in this way.

Dr. R. S. Hutton and Mrs. Moholy pointed the way to a solution of the problem, first referring to present U.S. practice whereby the purchaser of a photocopy declares that he will not use the copy other than for the purpose of private study, and secondly calling for a less cumbersome arrangement with the owners of copyright than the present one, which requires that in cases of doubt the copying agency has to make contact with the owner before proceeding with the copying. Time-saving being one of the greatest advantages of photocopying methods, it is desirable to have an automatic arrangement with copyright owners concerning the terms under which they are prepared to permit photocopying. It would then be possible for a copying agency like ASLIB to carry out its work without specific reference to publisher or author in any particular case.

It has been impossible in the course of a brief review to cover the many interesting points arising from this conference, but it is understood that the proceedings will be available in due course.

L. V. Chilton.

\section{BRITISH MUSEUMS DURING THE WAR YEARS}

"THE great task of museums and art galleries in this country during the War is to help preserve the basic sanity of our peoples and anything that can be done in this respect will be of greater ultimate value than most of us perhaps can now realize." These words are quoted from a message from Major S. F. Markham to members of the Museums Association in 1940. How the museums and art galleries have endeavoured to carry out this task is the subject of the leading article entitled "Endeavour and Achievement", appearing in the Museums Journal of April 1945. The information contained therein is based upon the many museum and art gallery reports received regularly at the offices of the Museums Association in London.

The author states that the large majority of these institutions have not only continued their activities throughout the war period, but also that they have considerably risen in public appreciation ; that their development, far from being curtailed by war conditions, has been greatly accelerated; and that "the support of museum and art gallery activities is now accepted as a normal service in any progressive city or town". Some of the causes leading to this satisfactory position are to be looked for in the popular short-term exhibitions of material supplied by government departments, the Council for the Encouragement of Music and the Arts, and many other organizations ; the co-operation of the museums and art galleries with government departments and the various Services in the provision of instruction for men and women in the Forces, and of loan-exhibits to camps, canteens and clubs; the arrangements made for discussion groups, concerts and art exhibitions; the many informative exhibits and talks dealing with the need for fuel economy, paper salvage, food production and so on ; and the special catering for the needs of leisure and thought by careful presentation of artistic, historical and scientific material.

That the need for such amenities is very real is proved by the overwhelming response of the public wherever they are provided, and the results fully demonstrate that where the service is well rendered, there will it be well received-indeed, even demanded. Nevertheless, the high attainments of even a majority of institutions must not be allowed to mask the fact that there are still far too many areas in Great Britain where the museum service is static, in decay, or even non-existent. Further, reports from even the larger museums continue to stress the need for expansion, better staffing, better working facilities, and more adequate expenditure; and there has been much criticism from not unimportant quarters. Even the writer of the article outlined above is aware of such matters, for he writes, ". . . it is of paramount importance that museums and art galleries should turn their present proud position to good account when peace returns. Directors and curators should take their rightful place in the circle of leading professional men and women who render notable service to the community". And again, "The Museums Association is staking a general claim for the advancement of museums and art galleries throughout the country, but local authorities must adapt this according to their individual needs". At this point, however, one may doubt whether all local authorities 